\title{
Fas-Induced Apoptosis Is a Rare Event in Sjögren's Syndrome
}

\author{
Maria Ohlsson, Kathrine Skarstein, Anne Isine Bolstad, Anne Christine Johannessen, \\ and Roland Jonsson
}

Broegelmann Research Laboratory (MO, KS, AIB, RJ) and Institute of Dentistry-Oral Pathology (ACJ), University of Bergen, Bergen, Norway

SUMMARY: The aim of this study was to perform a controlled in situ analysis on the incidence of apoptosis, investigate the expression of apoptosis-mediating proteins, and determine the frequency of apoptotic CD4 ${ }^{+}$and $\mathrm{CD} 8^{+} \mathrm{T}$ cells in Sjögren's syndrome (SS). The study was extended to patients with atrophy-fibrosis (AF) not related to SS, as well as to a control group. Immunohistochemistry and the terminal deoxynucleotidyl transferase mediated dUTP digoxigenin nick end labeling (TUNEL) method were applied to study the Fas and FasL expression and the incidence of apoptosis in salivary glands (SG) from patients with primary and secondary SS, AF, and controls. These methods were also combined to enable simultaneous detection of apoptotic and $\mathrm{CD}_{4}^{+}$or $\mathrm{CD}^{+}$T cells. Despite abundant expression of Fas and FasL in SS SG, apoptotic cells were not exceeding $1 \%$ in the foci of infiltrating mononuclear cells (IMC). Double staining showed that the frequency of apoptosis was low among both $\mathrm{CD}^{+}$and $\mathrm{CD}^{+}{ }^{+} \mathrm{T}$ cells. Only a few $\mathrm{TUNEL}^{+}$epithelial cells were found in all patient groups. Fas was expressed predominantly on SS IMC, single SS epithelial cells, and a few normal acinar cells, but not in AF SG. Although FasL was present on SS and AF IMC and epithelial cells, it was rarely detected in normal tissue. Consequently we demonstrate that Fas-induced apoptosis among SS SG is a rare event. Our findings support an earlier hypothesis indicating that IMC seem to be able to escape apoptosis, resulting in foci of inflammatory cells. Notably, however, no obvious correlation can be drawn to previous studies where a high incidence of apoptosis of epithelial cells was proposed as an important mechanism leading to decreased glandular function, which is a hallmark of SS. (Lab Invest 2001, 81:95-105).

\begin{abstract}
D rimary Sjögren's syndrome (SS) is an autoim1 mune, rheumatic disorder characterized by a chronic mononuclear cell infiltration into exocrine tissue such as salivary and lacrimal glands. Histologic studies show that these infiltrating cells are predominantly $\mathrm{CD}^{+}{ }^{+} \mathrm{T}$ lymphocytes surrounding blood vessels and enlarged ductal structures (Jonsson et al, 2000). The chronic inflammation probably leads to the typical functional loss of secretory activity and severe dryness in the mouth (xerostomia) and eyes (keratoconjunctivitis sicca). Additional symptoms of SS represent glandular and extraglandular manifestations, hypergammaglobulinemia, and production of autoantibodies such as anti-Ro/SSA, -La/SSB, and rheumatoid factor commonly detected in serum and saliva as well as in situ in salivary glands (SG) of SS patients (Halse et al, 1999a, 1999b, 2000; Reichlin et al, 1989; Tengnér et al, 1998). In addition to primary SS (pSS), the disease may occur as secondary SS (SSS) in conjunction with other rheumatic diseases, most fre-
\end{abstract}

Received October 5, 2000.

This work was supported by Stiftelsen Helse og Rehabilitering, Norske Kvinners Sanitetsforening, the European BIOMED program (BMH4CT96-0595), the Research Council of Norway (115563/320), and the Broegelmann Foundation.

Address reprint requests to: Dr. Maria Ohlsson, Broegelmann Research Laboratory, Armauer Hansen Building, 5021 Bergen, Norway. E-mail: Maria.Ohlsson@gades.uib.no quently rheumatoid arthritis (RA) or systemic lupus erythematosus (SLE) (Jonsson et al, 2000).

The mechanisms behind the characteristic glandular destruction seen in SG of SS patients still remain obscure. For some time, apoptotic cell death-generally involved in eliminating redundant, damaged, or infected cells in immunity, embryogenesis, and carcinogenesis-has been considered to play an important role in the pathogenesis of autoimmune disease (Mountz et al, 1996; Thompson, 1995). Among a broad range of gene products known to induce or block apoptotic events, particular focus has been put on the expression of Fas (APO-1, CD95) and its ligand FasL (CD95L) in human SS SG. Fas is a cell surface protein of the TNF receptor/nerve growth factor superfamily, constitutively expressed or induced after activation on a variety of cell types including $T$ lymphocytes (Itoh et al, 1991; Oehm et al, 1992). Expression of FasL, also a member of the TNF superfamily (Suda et al, 1993), was originally thought to be restricted to $T$ cells and natural killer cells during immune activation (Nagata, 1997). However, recent studies have shown that it can be constitutively expressed in various cell types, especially in immune-privileged tissues such as brain, testis, and malignant neoplasms (Hahne et al, 1996; Saas et al, 1997; Suda et al, 1995). It has also been detected in the epithelium of eye (Griffith et al, 1995), breast (Mullauer et al, 2000), and in SS (Kong et al, 1997; Nakamura et al, 1998; Polihronis et al, 1998). Fas-mediated apoptosis, in addition to the perforin- 
mediated pathway, constitutes the killing mechanisms of cytotoxic $\mathrm{T}$ cells. Upon proper antigen recognition through $\mathrm{MHC}$ and $\mathrm{T}$ cell receptor interaction and Fas/FasL ligation, apoptotic signals are transduced into the nucleus through a complex cascade of proteins, finally leading to apoptosis of the antigen presenting cell (Berke, 1995; Henkart, 1994).

In murine models, defective signaling and impeded apoptosis caused by mutations in Fas or Fas $L$ resulted in autoimmune disease as well as lymphadenopathy (Skarstein et al, 1997; Takahashi et al, 1994; Watanabe-Fukunaga et al, 1992). Corresponding mutations were not found in genes encoding Fas and FasL in pSS patients (Bolstad et al, 2000). However, it has been suggested that increased levels of Fasinduced apoptosis among epithelial cells could explain the characteristic acinar atrophy and consequently the dramatic reduction in salivary flow. On the other hand, increased expression of intracellular antiapoptotic molecules could lead to dysregulation of apoptosis and the formation of large foci of infiltrating mononuclear cells. Although several studies on Fas and FasL expression as well as apoptosis in SS SG have been presented, there is, to date, no consensus. Most notably, a wide range of apoptotic frequencies $(0.3 \%$ to $68 \%)$, sometimes quite high, have been detected by the terminal deoxynucleotidyl transferase mediated dUTP-digoxigenin nick end labeling (TUNEL) method in acinar and ductal epithelium (Kong et al, 1997; Manganelli et al, 1997; Matsumura et al, 1996, 1998; Nakamura et al, 1998; Polihronis et al, 1998; Sumida et al, 1997). Because of the wide discrepancy in previous studies of apoptosis in situ in SG of SS patients, the aims of the present study were to (1) perform a controlled TUNEL analysis on the incidence of apoptosis; (2) investigate the expression pattern of the apoptosis-related molecules, Fas and FasL; (3) study the T cell phenotype and distribution of apoptotic cells; (4) determine the frequency of CD4+ and CD8 $+\mathrm{T}$ cells infiltrating the epithelium; and (5) extend the investigation to patients with degenerative changes comparable but not related to SS, and to a control group.

\section{Results}

\section{Histologic Analysis}

Histologic analysis of SG from the 18 SS patients showed typical features of focal sialadenitis such as mononuclear cell accumulations representing large focal infiltrates surrounded by normal parenchyma, inflammatory cells sparsely distributed over the connective tissue, acinar atrophy, and enlarged ducts. In some of the patients, a particularly pronounced acinar epithelial atrophy could be observed, in others it was less dramatic. SG from the group of patients with non-SS related atrophy and fibrosis also shared these features, although to a lesser degree than SS SG and in conjunction with abundant fibrosis. Most importantly, chronic inflammation in patients with atrophy fibrosis was present as small and mixed cellular infiltrates rather than large lymphocytic foci. Control tissue did not exhibit any features of sialadenitis.

\section{Immunohistochemical Staining of Fas}

Table 1 and Figure 1A show the frequency of Fas expression detected by immunohistochemistry on acinar and ductal epithelial cells as well as on focal infiltrating mononuclear cells (IMC) in SG from patients with pSS, sSS, atrophy-fibrosis (AF), and normal individuals. Analysis of SS SG (Fig. 2A) revealed an intense and uniform membrane staining of Fas on numerous IMC. These cells were mainly concentrated in specific, often central, parts of the foci. Single lymphocytes expressing Fas could also be observed scattered over the interstitium. Expression was rare among epithelial cells, but interestingly, two separate morphological categories of

Table 1. Percentage of Cells Expressing Fas and FasL and Apoptotic Index in Salivary Glands from Patients with Primary and Secondary Sjögren's Syndrome, Patients with Degenerative Changes Not Related to Sjögren's Syndrome, and from Normal Individuals

\begin{tabular}{llcccc}
\hline & & \multicolumn{3}{c}{ Percentage of Positive Cells \pm SEM in Patient Group } \\
\cline { 3 - 6 } Staining & Tissue Area & $\mathrm{pSS}$ & $\mathrm{SSS}$ & $\mathrm{AF}$ & $\mathrm{N}$ \\
\hline Fas $^{a}$ & $\mathrm{AE}^{c}$ & $0.30 \pm 0.13$ & $0.50 \pm 0.14$ & 0 & $0.48 \pm 0.21$ \\
& $\mathrm{DE}^{c}$ & $0.63 \pm 0.15$ & $1.49 \pm 0.65$ & 0 & 0 \\
FasL $^{a}$ & $\mathrm{IMC}$ & $4.00 \pm 0.35$ & $6.71 \pm 1.36$ & - & - \\
& $\mathrm{AE}^{c}$ & $0.17 \pm 0.08$ & $0.32 \pm 0.10$ & $0.20 \pm 0.13$ & 0 \\
& $\mathrm{DE}^{c}$ & $0.79 \pm 0.20$ & $1.06 \pm 0.26$ & $0.88 \pm 0.25$ & 0 \\
Apoptotic & $\mathrm{IMC}$ & $2.58 \pm 0.53$ & $1.95 \pm 0.20$ & - & - \\
Index & $\mathrm{AE}^{c}$ & $0^{b}$ & $0^{b}$ & $0^{b}$ & $0^{b}$ \\
& $\mathrm{DE}$ & $0^{b}$ & $0^{b}$ & $0^{b}$ & $0^{b}$ \\
& $\mathrm{IMC}$ & $0.79 \pm 0.18$ & $0.87 \pm 0.20$ & - & -
\end{tabular}

pSS, patients with primary Sjögren's syndrome $(n=9)$; sSS, patients with secondary Sjögren's syndrome $(n=9)$; AF, patients with degenerative changes (atrophy-fibrosis) not related to Sjögren's syndrome $(n=7)$; N, normal individuals $(n=5)$; AE, acinar epithelial cells; DE, ductal epithelial cells; IMC, infiltrating mononuclear cell; SEM, standard error of the mean.

${ }^{a}$ Cells with $50 \%$ strong or moderate membrane staining were regarded as positive.

${ }^{b}$ TUNEL stained cells were present but so rare that the apoptotic index $=0$.

${ }^{c}$ Lymphocytes were by immunohistochemistry shown to infiltrate epithelial areas (see Table 2 ). 
A

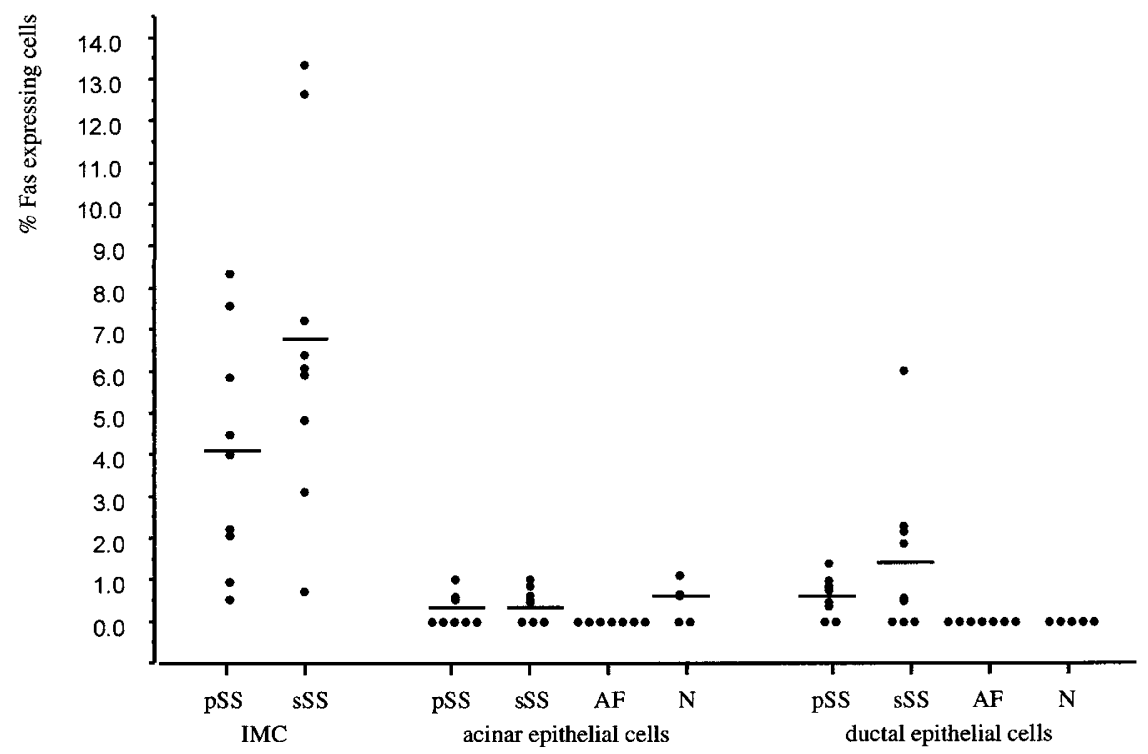

B
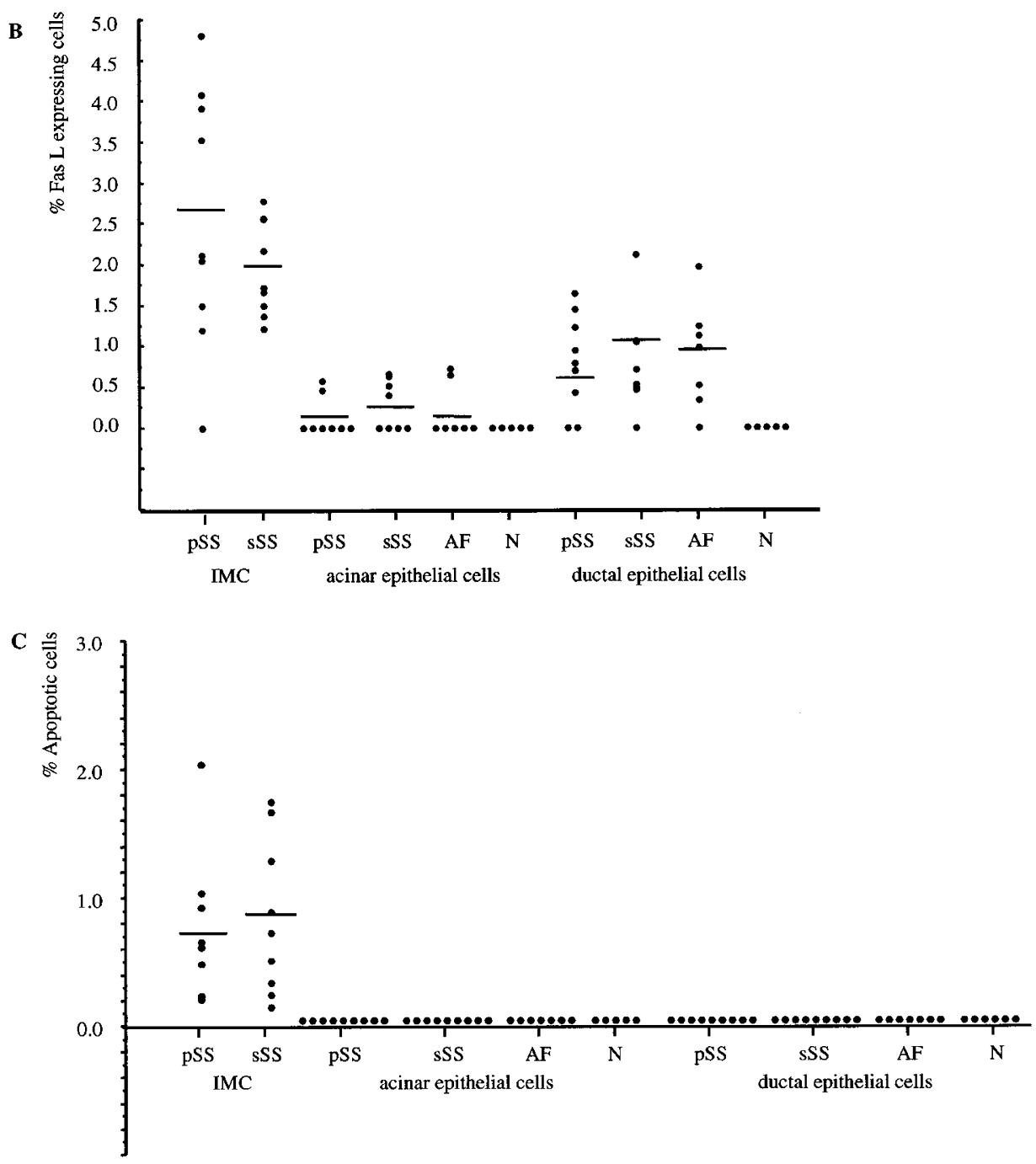

Figure 1.

Distribution of Fas (A) and FasL (B) expression levels and frequencies of apoptotic cells (C) in salivary glands (SG) from patients with primary and secondary Sjögren's syndrome (pSS, $n=9$; SSS, $n=9$ ), non-SS-related atrophy and fibrosis (AF, $n=7$ ), and normal individuals (N, $n=5$ ). Immunohistochemistry and the TUNEL method were applied on frozen tissue sections. Positive cells were counted among focal infiltrating mononuclear cells (IMC) and acinar and ductal epithelial cells The value of each dot represents the frequency of positive cells for each patient, and the line indicates the mean frequency for the different cell types in the individual patient groups. 



Figure 2.

Fas and FasL expression (red) were detected in situ in SG from patients with SS and normal controls by application of immunohistochemistry. A, In SS SG, Fas ${ }^{+}$ cells were found predominantly among focal $I M C$ and sparsely in acinar and ductal epithelium ( $A E$ and $D E$, respectively). B, Expression of Fas was rarely detected in normal SG, but could sometimes be found on lymphocytes in interstitial areas and on acinar epithelial cells. C, FasL was expressed among some scattered focal IMC and occasionally in epithelial areas in SS SG. D, In normal SG, FasL expression was rarely detected.

staining were found. A uniform membrane staining similar to that on focal IMC was detected on cells infiltrating certain acini as well as the basal membrane of some ducts. These cells were sometimes hard to distinguish properly from epithelial cells based only on their morphology in the section. However, immunohistochemical staining confirmed increased levels of $T$ cells infiltrating epithelial areas (Table 2, discussed below). In addition, Fas was sometimes observed on the luminal surface of ductal epithelium as a faint staining and occasionally as a grainy mucous staining in acinar epithelium. One could assume that both of these latter observations would illustrate transportation of soluble Fas molecules. Altogether, there was no significant difference in the frequency of $\mathrm{Fas}^{+}$cells between pSS and sSS patients.

In AF SG, membrane-bound Fas was sometimes detected in the mixed chronic infiltrates as well as on single lymphocytes scattered in the interstitium. No $\mathrm{Fas}^{+}$acinar cells could be observed, but a weak staining was present on certain ductal cells, altogether indicating poor expression of Fas in AF SG. In control SG, Fas staining was sparsely detected. A small number of positive lymphocytes were found scattered in interstitial areas and among epithelial cells, positive acinar cells were rare, whereas no expression could be detected on the ducts (Fig. 2B). In conclusion, the frequencies of $\mathrm{Fas}^{+}$cells were increased in ductal epithelium of SS SG (pSS: $P=0.023, P_{\text {corr }}=0.116$; sSS: $\left.P=0.044, P_{\text {corr }}=0.221\right)$. Moreover, compared with AF patients, also affected by chronic, but mixed and less intense inflammation, Fas expression was significantly increased on pSS ductal cells $(P=0.004$, $\left.P_{\text {corr }}=0.022\right)$, and increased on sSS ductal cells $(P=$ $\left.0.011, P_{\text {corr }}=0.053\right)$ and on sSS acinar cells $(P=$ $\left.0.011, P_{\text {corr }}=0.053\right)$. However, the infiltration of $\mathrm{T}$ cells was also significantly increased in ductal epithelium of pSS and sSS patient groups (described below). Therefore, $T$ cells might have contributed to the increased expression of Fas in SS SG ductal epithelium. Among acinar cells in AF SG, the frequency of $\mathrm{Fas}^{+}$ cells was decreased compared with normal SG ( $P=$ $\left.0.025, P_{\text {corr }}=0.126\right)$.

\section{Immunohistochemical Staining of FasL}

The distribution of cells immunohistochemically stained for FasL expression in the four patient groups is presented in Table 1 and Figure 1B. Briefly, mem- 
Table 2. Percentage of $\mathrm{CD}^{+}$and $\mathrm{CDB}^{+} \mathrm{T}$ Cells and Double Positive $\mathrm{CD}^{+}$or $\mathrm{CDB}^{+}$Apoptotic Cells in Salivary Glands from Patients with Primary and Secondary Sjögren's Syndrome and Normal Individuals

\begin{tabular}{ccccc}
\hline & & \multicolumn{2}{c}{ Percentage of Positive Cells \pm SEM in Patient Group } \\
\cline { 3 - 5 } Staining & Tissue Area & pSS & sSS & N \\
\hline CD4 $^{a}$ & AC & $1.20 \pm 0.71$ & $0.78 \pm 0.27$ & $0.41 \pm 0.29$ \\
& DC & $6.64 \pm 1.46^{c}$ & $5.44 \pm 1.95^{c}$ & $0.78 \pm 0.33$ \\
CD8 $^{a}$ & IMC & $50.9 \pm 7.62$ & $54.8 \pm 8.69$ & - \\
& AC & $1.34 \pm 0.82$ & $1.03 \pm 0.44$ & 0 \\
CD4TUN $^{a}$ & DC & $4.24 \pm 0.79$ & $3.13 \pm 0.96$ & $1.12 \pm 0.50$ \\
& IMC & $21.0 \pm 2.60$ & $35.3 \pm 5.14$ & - \\
CD8TUN $^{a}$ & AC & $0^{b}$ & $0^{b}$ & $0^{b}$ \\
& DC & $0^{b}$ & $0^{b}$ & - \\
& IMC & $0.13 \pm 0.08$ & $0.14 \pm 0.08$ & $0^{b}$ \\
& AC & $0^{b}$ & $0^{b}$ & $0^{b}$ \\
& DC & $0^{b}$ & $0^{b}$ & - \\
\hline
\end{tabular}

pSS, patients with primary Sjögren's syndrome $(n=6)$; SSS, patients with secondary Sjögren's syndrome $(n=6)$; N, normal individuals $(n=5)$; AC, acinar cells DC, ductal cells; IMC, infiltrating mononuclear cells; SEM, standard error of the mean.

${ }^{a} \mathrm{CD4}^{+}$and $\mathrm{CD}^{+} \mathrm{T}$ cells with $50 \%$ strong or moderate membrane staining were regarded as positive.

${ }^{b}$ TUNEL stained cells were present but so rare that the apoptotic index $=0$.

${ }^{c}$ Significantly increased expression compared with normal controls; $p<0.05$ as determined by the Mann-Whitney $U$ test and Bonferroni correction of multiple comparisons.

brane FasL staining was observed on focal IMC as well as on single lymphocytes scattered in the interstitium of SS SG. However, $\mathrm{FasL}^{+}$cells were less frequent and were spread over the foci rather than clustered in certain areas, as was the case for Fas stained cells (Fig. 2C). In AF SG, FasL ${ }^{+}$inflammatory cells were occasionally scattered in the interstitium but rarely in the mixed chronic infiltrates. A few acinar and ductal epithelial cells of SS as well as AF SG were $\mathrm{FasL}^{+}$. The staining was predominantly located in luminal mucous parts indicating possible transportation of soluble FasL. In addition, $\mathrm{FasL}^{+}$inflammatory cells were occasionally observed between basal membrane cells of the ductal epithelium. In summary, there was no significant difference in the frequency of FasL expressing cells between pSS and sSS patients. Interestingly, FasL expression in ductal epithelium was significantly increased on sSS and AF SG (sSS: $P=$ $\left.0.006, P_{\text {corr }}=0.027 ; \mathrm{AF}: P=0.009, P_{\text {corr }}=0.047\right)$ and increased on pSS $\left(P=0.013, P_{\text {corr }}=0.064\right)$ compared with normal SG tissue where FasL was rarely detected (Fig. 2D). Based on the same arguments, one cannot exclude that infiltrating lymphocytes may have contributed to the increased FasL expression in ductal epithelium of AF and SS SG.

\section{Detection of Apoptotic Cells by the TUNEL Method}

The frequency of apoptotic cells was determined by the TUNEL method on frozen SG tissue sections from patients and controls and is presented in Table 1 and Figure 1C. Although apoptotic cells were present and often colocalized in SS SG focal IMC, the frequency was lower than $1 \%$ in both pSS and sSS patients. In our study, there was no correlation between the incidence of apoptosis and foci size or score. Nor did there seem to be a correlation with the degree of acinar atrophy. Only a few TUNEL ${ }^{+}$cells were found in acinar and ductal epithelium, not enough to contribute to an apoptotic index above 0\% (Fig. 3A). These observations were also analogous to AF as well as normal tissue. The apoptotic index among epithelial cells is consequently presented as $0 \%$ in all patient groups. A few scattered apoptotic cells were found in the interstitium and the connective tissue of all patient groups, sometimes in large areas of the connective tissue in AF patients, indicating active fibrosis. As expected, tonsillar tissue sections, included as positive controls in each experimental run, comprised $\mathrm{TUNEL}^{+}$cells in the basal light zone of germinal centers (Fig. 3B).

\section{Simultaneous Detection of Apoptosis and T Cell Phenotype}

To determine the phenotype of apoptotic T cells, we developed a combined protocol for immunohistochemistry and the TUNEL method on frozen tissue sections. Foci and epithelial tissue were analyzed in SS and normal SG (Table 2). T cells were observed in interstitial areas but rarely in acini or ducts in normal SG. In SS SG, CD4 ${ }^{+}$cells were the most predominant, although both $\mathrm{CD}^{+}$and $\mathrm{CD}^{+}{ }^{+} \mathrm{T}$ cell subsets were spread over the focal areas. However, the incidence of apoptosis was found to be equal among $\mathrm{CD}^{+}$and $\mathrm{CD}^{+}$cells. Both cell subsets were often found in interstitial areas and infiltrating ductal epithelium, and to a lesser degree also in acini (Fig. 4, A and B). Most notably, compared with normal SG, there was a significantly increased level of infiltration of $\mathrm{CD}^{+}$cells in SS ductal areas (pSS: $P=0.006, P_{\text {corr }}=0.012$; sSS: $\left.P=0.017, P_{\text {corr }}=0.035\right)$. Infiltration of $\mathrm{CD}^{+}$cells was increased in pSS ductal areas $\left(P=0.028, P_{\text {corr }}=\right.$ $0.056)$ as well as in sSS acini $\left(P=0.035, P_{\text {corr }}=\right.$ 

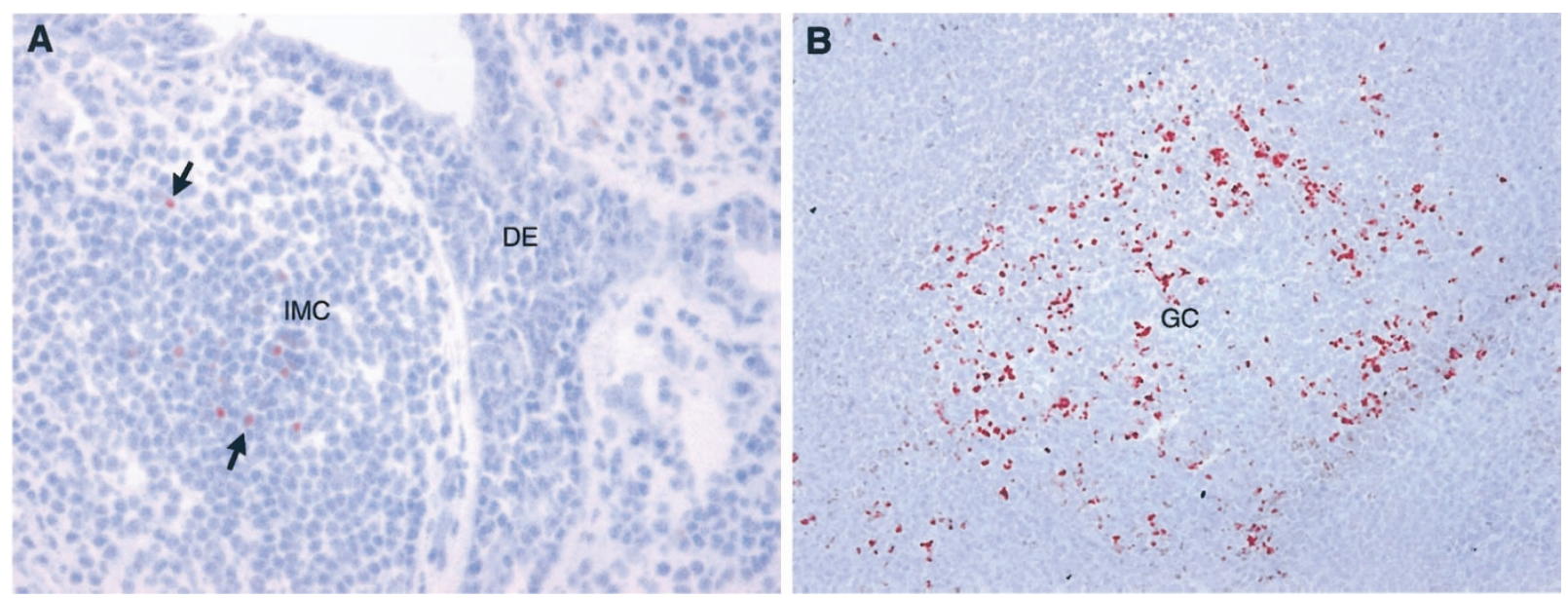

\section{Figure 3.}

Apoptotic cells (red) in frozen SG tissue sections from patients with SS and normal tonsillar tissue were labeled in situ by application of the TUNEL method. A, Only a few apoptotic cells (examples indicated by arrows) could be found among focal IMC in SS SG. Apoptosis of epithelial cells was rarely detected (DE, ductal epithelium). B, TUNEL ${ }^{+}$cells were readily detected in the germinal centers $(G C)$ of normal tonsil, which was included as positive control.

0.069). Apoptotic cells were readily detected in normal tonsil tissue sections included as positive controls.

\section{Discussion}

Despite abundant knowledge about significant characteristics of SS, the trigger that causes autoimmunity and the final loss of secretory function is still a mystery. During the last years, several investigators have put particular focus on the possible interference of inflammatory $T$ lymphocytes in epithelial cell destruction in SS by Fas-mediated apoptosis. In these in situ studies on SG from SS patients, it is most notable that both apoptotic frequencies and expression levels of apoptosis-related proteins are widely diverse. Some indicate that diminished salivary flow is a result of an increased frequency of apoptosis among ductal epithelial cells, whereas others indicate that it is an effect of augmented acinar apoptosis (Manganelli et al, 1997; Matsumura et al, 1998).

Interestingly, in contrast to earlier reports, we found that despite elevated expression of Fas and to a lesser extent also FasL among focal IMC and epithelial cells in SS SG, apoptosis was still a rare event. Thus, despite enabled Fas-mediated apoptosis, these findings may indicate that the transmission of death signals into the nucleus might have been blocked. According to our findings, escape from Fas-induced apoptosis could explain the formation of massive inflammatory infiltrates in SS SG, a hypothesis also supported by others (Kong et al, 1997; Matsumura et al, 1998; Polihronis et al, 1998). Most important, the incidence of apoptosis among epithelial cells was not increased in pSS and sSS compared with normal or AF SG. Only a few TUNEL positive cells were found in all patients groups. Our findings are supported by a report on low frequencies of ductal apoptosis ( $0.25 \pm$ $0.25 \%$ in SS SG, $0.03 \pm 0.04 \%$ in normal SG) (Nakamura et al, 1998) and by a study on normal oral epithelium where $0.4 \pm 0.1 \%$ TUNEL positive cells were detected (Loro et al, 1999). There was no signif- icant difference between pSS and sSS patients in the frequency and localization of apoptotic cells, nor of Fas- and FasL-expressing cells.

In an overall comparison of previous reports on TUNEL staining of epithelial cells in SS SG, apoptotic frequencies varied from "a few" to $37 \%$ in acini, $0.3 \%$ to $68 \%$ in ducts, and $0 \%$ to $21 \%$ among IMC. These findings should be compared with frequencies varying from $0 \%$ to $19 \%$ in normal SG (Kong et al, 1997; Manganelli et al, 1997; Matsumura et al, 1998; Nakamura et al, 1998; Polihronis et al, 1998; Sumida et al, 1997). The whole process of apoptosis has been described as spanning just three hours. Moreover, neighboring as well as invading phagocytic cells generally engulf and eliminate apoptotic bodies immediately after their formation, which is why detection of TUNEL positive cells in a tissue section should be considered as a highly momentary event (Bursch et al, 1990). Consequently, the very high apoptotic indexes presented for SS as well as normal SG in previous reports would probably correspond to total clearance rather than actual diminished volume fraction of the cell subsets studied. Furthermore, a direct correlation between expression of Fas and FasL and apoptotic index cannot be accurately performed in the majority of these earlier studies, because immunohistochemistry and assessment of apoptosis were executed on frozen and formalin-fixed sections, respectively.

By developing a combined avidin biotin complex (ABC) and TUNEL method on frozen tissue sections, we showed that focal $\mathrm{CD}^{+}$and $\mathrm{CD}^{+}$cells go through apoptosis at the same low rate in SS SG. This can be compared with a study indicating increased susceptibility to Fas-induced apoptosis of peripheral $\mathrm{CD} 4^{+}$cells but not of $\mathrm{CD}^{+}$cells in SS patients (Zeher et al, 1999). We also found that $C D 4^{+}$as well as $C D 8^{+}$ cells frequently infiltrated ductal epithelium, especially in SG affected by severe sialadenitis. Most notably, we found significantly increased levels of Fas and FasL expression as well as T cell infiltration in SS ductal 

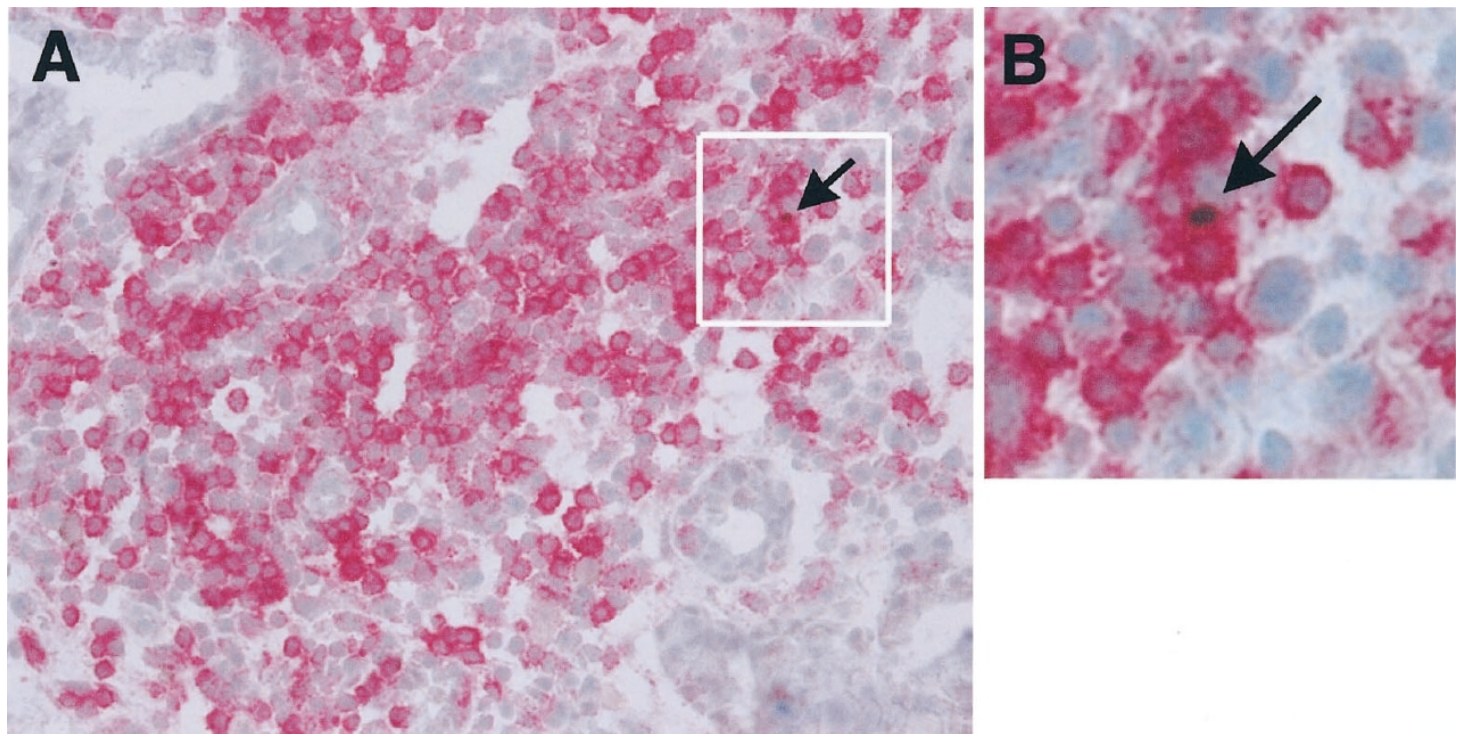

Figure 4.

Simultaneous detection of apoptosis and CD4 ${ }^{+}$T cells in SS SG and normal tonsillar tissue. This was enabled on one single frozen tissue section by a combined procedure for immunohistochemistry and the TUNEL method. A, Double positive apoptotic (black) and CD4 ${ }^{+}$(red) cells were rare, but could occasionally be found in foci of IMC. $\mathrm{CD}^{+} \mathrm{T}$ cells were spread over the foci and did frequently infiltrate ductal epithelium and, to a lesser degree, also acinar epithelium. B, A CD4 ${ }^{+}$apoptotic cell among single stained CD4 ${ }^{+}$cells in SS SG foci (magnification of the area in the white box in A).

epithelium. Based only on their morphology, $\mathrm{T}$ cells are sometimes difficult to identify among epithelial cells in a tissue section, and so they occasionally might have been counted as epithelial cells by mistake in this study. Thus, one cannot exclude the possibility that the high levels of $\mathrm{T}$ cells infiltrating the ducts might have contributed to the significantly increased levels of Fas and FasL expression presented here, and, hypothetically, also in earlier reports. Only an immunohistochemical doublestaining, which is troublesome to perform on two membrane-bound molecules, would have elucidated the true situation. However this technical problem might actually further support our finding of low incidence of apoptosis despite Fas and FasL expression in SS SG, especially regarding epithelial cells. As determination of cell phenotype was not included in the earlier studies of apoptosis in situ, one cannot exclude the possibility that a portion of the apoptotic cells they detected in epithelium actually were activated $\mathrm{T}$ cells expressing Fas and FasL.

TUNEL has become a widely used staining method to assist in detection of apoptotic cells in tissue. However, despite its apparent simplicity, a number of critical criteria have to be applied to obtain an accurate delineation of apoptosis (Huppertz et al, 1999; Labat-Moleur et al, 1998; Negoescu et al, 1996; Yasuda et al, 1995). The sensitivity of the TUNEL assay is important because single strand breaks of DNA are found in other biological situations such as replication and mitosis. Therefore, low levels of DNA breakage exist naturally in cells, which is why false positive results easily can be obtained, eg., with excessive pretreatment with proteinase $\mathrm{K}$ or excess TdT. The objective of TUNEL procedures can consequently be known as an attempt to determine the threshold at which only cells with a high degree of DNA fragmentation are labeled. The main drawback with TUNEL, as emerging in the critical evaluations, is the fact that it is very sensitive for tissue processing. Fixation and pretreatments (paraffin sections) are especially critical factors in the detection system, and careful comparison with the control tissue is of utmost importance (Labat-Moleur et al, 1998; Negoescu et al, 1996). An evaluation of the TUNEL method was performed on frozen as well as formalin-fixed paraffin-embedded sections of $M$. tuberculosis-infected mouse lung at our department. In frozen tissue, apoptotic frequencies were equal or only slightly lower than in formalin-fixed sections, pretreated with $20 \mu \mathrm{g} / \mathrm{ml}$ proteinase $\mathrm{K}$ for 15 minutes at $37^{\circ} \mathrm{C}(\mathrm{T}$. Mustafa, University of Bergen, personal communication, 2000).

In addition to membrane proteins such as Fas and FasL, apoptotic signaling pathways involve a complex intracellular cluster of pro- and antiapoptotic proteins. These proteins bind in homo- and heterodimers, which is why the expression ratio determines the final destiny of the Fas stimulated cell. Bcl-2, a member of the proto-oncogene family known to interact and control the sensitivity and resistance to apoptosis (Korsmeyer, 1992; Zha et al, 1996), has indeed been shown to be expressed on the majority of SS SG IMC. However, these cells have also been reported to produce increased levels of the apoptosis-promoting Bax protein (Kiefer et al, 1995). Even more confusing, reports on the level of $\mathrm{Bcl}-2$ expression among SS epithelial cells are inconsistent despite staining with the same antibody (Kong et al, 1998; Manganelli et al, 1997). Altogether, these findings demonstrate the complexity of the apoptotic protein puzzle and how unreliable it is to predict the fate of a cell based solely on the expression level of one or a few of these 
proteins. Furthermore, factors including cytokines such as IL-2, IL-10, and TNF produced in SS patients (Halse et al, 1999b; Taga et al, 1993), as well as interactions with adhesion molecules, may all contribute to escape from apoptotic signals.

Hypothetically, apoptosis of SG epithelial cells might occur at earlier stages of the disease progression, and it might not be possible to detect it in tissue from our patients who were already affected by SS at the time of biopsy. Among the SS patients studied here, there are dissimilarities in focus score number and/or size as well as in the degree of acinar atrophy. This might represent a wide range of inflammatory activity and thus a wide range in the development of SS in humans. Animal models for exocrinopathy provide the potential to follow the development of sialadenitis from early focal lymphocytic infiltration to glandular destruction and decreased secretory response. In accord with our study, no obvious correlation was found between Fas expression and the susceptibility to undergo apoptosis among focal IMC of submandibular salivary glands of the MRL-Ipr and $\mathrm{MRL}+/+$ murine SS models where none or less than $0.1 \%$ of the IMC were TUNEL stained (Skarstein et al, 1997). Mutation analysis on the promoters as well as all exons of Fas and Fas $L$ showed that there are probably no crucial defects in these genes in human SS (Bolstad et al, 2000). This is why studies on apoptotic levels in submandibular salivary glands from NOD and NODscid mice (also murine models of SS although expressing functional Fas protein, the last lacking B- as well as $T$ cells) are of special interest. Most interestingly, in a recent study, low and similar numbers of TUNEL positive epithelial cells were found in these mice compared with control $\mathrm{C} 57 \mathrm{Bl} / 10$ mice. Furthermore, this was observed during early as well as effector phases of the sialadenitis despite aberrant expression of Fas, FasL, and bcl-2 (S. C. A. van Blokland et al, Erasmus University, Rotterdam, personal communication, 2000). If these findings in murine models also represent the condition during development of human SS, one might have to rule out the potency of Fas-induced apoptosis as an important mechanism leading to decreased glandular function found in SS.

In a longitudinal study of pSS and sSS patients, salivary secretion was not altered over time despite a significantly increased focus score (Jonsson et al, 1993), demonstrating the lack of influence of cytotoxic $\mathrm{T}$ cells in functional capacity. As the fractional volume of acini in SS SG is decreased, although not always significantly compared with normal tissue, one could imply that reduced salivary flow is a late sign of SG disease compared with sialadenitis. In the current report we show that the incidence of apoptosis in SS $S G$ is low. Although a slow progression of apoptotic epithelial cell destruction may take place, it does not seem to be as aggressive as suggested in earlier studies. However, autoantibodies produced at the site of inflammation and impaired neurological signaling represent other factors that might contribute to the reduced salivary flow (Humphreys-Beher et al, 1999).
Thus, further investigations into the physiological effect of these factors as well as efforts to identify the triggers of the autoimmune reaction must be performed before the role of apoptosis in SS can be fully evaluated.

\section{Materials and Methods}

\section{Patients and Controls}

Minor submucosal labial SG biopsies (Daniels, 1984; Greenspan et al, 1974) were obtained, transported in Histocon (Histolab, V. Frölunda, Sweden), frozen in methylbutane by liquid nitrogen, and stored at $-70^{\circ} \mathrm{C}$. Eighteen patients fulfilling the European classification criteria for SS (Vitali et al, 1993) were studied. Nine of these patients (eight females and one male, mean age 52 , ranging from 35 to 78 years) suffered from pSS. The other nine patients (all females, mean age 62, ranging from 45 to 84 years) had sSS, fulfilling other connective tissue disease criteria such as SLE $(n=4)$ and RA $(n=5)$. Six of 18 SS patients were serological positive for autoantibodies to Ro/SSA and/or La/SSB. Histologic evaluation defined the following focus scores: pSS: mean 3.6 (range 2 to 8 ) and sSS: mean 3.2 (range 1 to 8 ). In addition, seven patients with SG atrophy and fibrosis not related to SS were studied. These patients (six females, one male, mean age 59, ranging from 49 to 68 years) had no focus score but sparse infiltration of mononuclear cells in the SG and negative serology. As controls, SG were obtained from 5 individuals (three females, two males, mean age 34, ranging from 19 to 53 years) evaluated for sicca symptoms but showing no SG sialadenitis and negative serology. Patients were recruited from Haukeland University Hospital (Bergen, Norway). The study was approved by the Committee of Ethics at the University of Bergen and informed consent was obtained from all patients.

\section{Immunohistochemical Staining}

Fas and FasL expressions were detected on freshly cut $5-\mu \mathrm{m}$ sections by applying a modified version of the ABC method (Hsu et al, 1981). Briefly, after stepwise fixation in $50 \%$ acetone at $4^{\circ} \mathrm{C}$ for 30 seconds and $100 \%$ acetone at $4^{\circ} \mathrm{C}$ for 5 minutes, endogenous peroxidase activity was quenched with $0.3 \% \mathrm{H}_{2} \mathrm{O}_{2}$ in TBS (50 mм Tris- $\mathrm{HCl} \mathrm{pH} 7.5,150 \mathrm{~mm} \mathrm{NaCl}$ ) for 5 minutes. To avoid background staining from endogenous biotin, sections were treated with Avidin D and Biotin blocking solution (Vector Laboratories, Burlingame, California) for 15 minutes each. Nonspecific binding was blocked by incubation with either $5 \%$ normal horse serum (Fas staining) or 10\% normal swine serum (FasL staining) in $4 \%$ bovine serum albumin (BSA)/PBS, pH 7.15, for 30 minutes. The sections were then incubated for 60 minutes with mouse antihuman Fas IgG1 (clone UB2, Medical \& Biological Laboratories, Nagoya, Japan; diluted 1:100) or polyclonal rabbit antihuman FasL (Oncogene Research Products, Calbiochem, Cambridge, Massachusetts; diluted 1:5). Then, secondary antibody was 
applied for 30 minutes; either biotin-labeled horse antimouse IgG (Vector) for Fas staining or biotinlabeled swine antirabbit (DAKO A/S, Glostrup, Denmark) for FasL staining; both diluted 1:200 in the serum blocking solution. Binding of secondary antibodies was detected by incubation with Vectastain avidin-biotin-horseradish peroxidase (HRP) complex (Vector) for 30 minutes. Staining was finally developed with a substrate consisting of $\mathrm{a}_{2} \mathrm{O}_{2}$ and 3-amino-9ethylcarbazol (AEC) buffer for 15 minutes. Sections were counterstained with Mayer's hematoxylin for 10 seconds and mounted with aqueous mounting medium. All procedures were performed at room temperature. Except for the protein-blocking step, the sections were washed with TBS for $2 \times 3$ minutes after each incubation. Negative controls were performed by incubation with either normal horse serum or normal swine serum instead of primary antibody.

\section{In Situ Labeling of Apoptotic Cells}

DNA fragmentation during apoptosis was detected in situ by performing a modified version of the TUNEL method (Gavrieli et al, 1992; Surh and Sprent, 1994). Briefly, 5- $\mu \mathrm{m}$ cryostat sections were dried, fixed with freshly prepared $10 \%$ paraformaldehyde (PFA)/PBS for 30 minutes, and washed with TBS. Activity of endogenous peroxidase was inactivated by exposure to $0.1 \% \mathrm{H}_{2} \mathrm{O}_{2}$ in TBS for $2 \times 15$ minutes followed by washing in TBS. Sections were equilibrated in thymidine-dioxynucleotidyl transferase (TdT) buffer (0.5 M cacodylate, $\mathrm{pH} 6.8,1 \mathrm{~mm} \mathrm{CoCl}_{2}, 0.5 \mathrm{~mm}$ dithiothreitol (DTT), $0.05 \% \mathrm{BSA}$ and $0.15 \mathrm{M} \mathrm{NaCl}$ ) at $37^{\circ} \mathrm{C}$, and then covered with TdT buffer containing $0.1 \mathrm{U} / \mu \mathrm{l}$ TdT (Boehringer-Mannheim, Mannheim, Germany) and $8 \mathrm{nmol} / \mathrm{ml}$ digoxigenin conjugated dUTP (Boehringer-Mannheim) in a humidified chamber for 1 hour at $37^{\circ} \mathrm{C}$. The reaction was stopped by washing in TBS, sections were then blocked by washing in TBS supplemented with $2 \%$ fetal calf serum (FCS)/TBS), followed by sheep anti-digoxigenin IgG (BoehringerMannheim; diluted to $5 \mu \mathrm{g} / \mathrm{ml}$ in blocking serum) applied for 1 hour. After washing in TBS and soaking in $10 \%$ pooled human serum in $2 \%$ FCS/TBS, sections were incubated with HRP-conjugated rabbit antisheep (DAKO A/S, Glostrup, Denmark; diluted 1:100 in blocking serum) for 1 hour. After washing in TBS, $\mathrm{TUNEL}^{+}$cells were visualized by incubation with AEC buffer containing $\mathrm{H}_{2} \mathrm{O}_{2}$ for 15 minutes. All steps except incubation with TdT reaction buffer were carried out at room temperature. The sections were counterstained in Mayer's hematoxylin and mounted with aqueous mounting medium. Negative controls included tissue sections incubated as described above, although omitting TdT and dUTP. Tonsillar tissue sections were included as positive controls.

\section{Simultaneous Immunohistochemical Staining and Labeling of Apoptotic Cells}

Double staining of CD4 or CD8 expression and DNA fragmentation during apoptosis was detected in situ by performing a combined and modified version of the $A B C$ and TUNEL methods. Briefly, sections were fixed according to TUNEL procedures. After quenching of endogenous peroxidase, immunohistochemistry was performed. Primary antibodies were monoclonal mouse antihuman CD4 or mouse antihuman CD8 (clone SK3 and SK1, respectively; Becton Dickinson, New Jersey; diluted 1:50). Nonspecific binding was blocked with $1 \%$ normal goat serum in TBS before addition of biotin conjugated goat antimouse IgG1 antibody (Caltag Laboratories, Burlingame, California) diluted 1:300 in blocking solution. Binding was detected by sequential incubation with Vectastain ABCalkaline phosphatase kit for 30 minutes and red alkaline phosphatase containing Levamisol (Vector) for 25 minutes. Then the TUNEL protocol was performed as described, except that bound HRP was detected by incubation with $\mathrm{DAB} / \mathrm{NiCl}_{2}$ (Vector) for 4 minutes and sections were counterstained in 50\% Mayer's hematoxylin for 3 seconds. Positive and negative controls were included as described.

\section{Evaluation of Staining and Statistical Analysis}

SG tissue was divided into three morphological areas: focal IMC (foci), and acinar and ductal epithelium. Cells were counted using a light microscope with a grid and a 40x ocular. The size of the foci of inflammatory cells was divided into three categories: (1) less than 50 cells, (2) 51 to 500 cells, and (3) more than 500 cells. An average of approximately 150 acinar cells, 150 ductal cells, and 400 focal IMC (total of 700 cells) were counted within randomly selected fields in each specimen. Cells with more than $50 \%$ of the cell membrane immunohistochemically stained were counted as positive. Only morphologically characteristic apoptotic cells with condensed nuclei or nuclear fragments were quantified as positive, whereas the peripheries of the sections and other artefacts leading to false positive staining were excluded. The percentages of positive cells stained for Fas, FasL, CD4, CD8, TUNEL, and of double positive CD4/CD8 and TUNEL cells are presented in tables and figures. Nonparametric analysis of variance among the independent samples was performed using the Kruskal-Wallis test. Mann-Whitney $U$ test was used for comparing frequencies between pSS, sSS, and AF patients and healthy controls and between AF and pSS or sSS patients $(P)$. Adjustments for multiple comparisons were performed for five (Table 1) and two (Table 2) outcomes using the Bonferroni correction $\left(P_{\text {corr }}\right)$. After correction, $P_{\text {corr }}$ values less than 0.05 were considered statistically significant.

\section{Acknowledgements}

We wish to thank Gunnvor Øijordsbakken, Marianne Eidsheim, and Turid Tynning for their excellent technical assistance. Special gratitude goes to Karl Brokstad for magnificent help with the photographs and to Dr Elling Ulvestad for provision of serological data and for valuable discussions. 


\section{References}

Berke G (1995). The CTL's kiss of death. Cell 81:9-12.

Bolstad AI, Wargelius A, Nakken B, Haga H-J, and Jonsson $\mathrm{R}$ (2000). Fas and Fas ligand gene polymorphisms in primary Sjögren's syndrome. J Rheumatol 27:2397-2405.

Bursch W, Kleine L, and Tenniswood M (1990). The biochemistry of cell death by apoptosis. Biochem Cell Biol 68:10711074.

Daniels TE (1984). Labial salivary gland biopsy in Sjögren's syndrome: Assessment as a diagnostic criterion in 362 suspected cases. Arthritis Rheum 27:147-156.

Gavrieli Y, Sherman Y, and Ben-Sasson SA (1992). Identification of programmed cell death in situ via specific labelling of nuclear DNA fragmentation. J Cell Biol 119:493-501.

Greenspan JS, Daniels TE, Talal N, and Sylvester RA (1974). The histopathology of Sjögren's syndrome in labial salivary gland biopsies. Oral Surg Oral Med Oral Pathol 37:217-229.

Griffith TS, Brunner T, Fletcher SM, Green DR, and Ferguson TA (1995). Fas ligand-induced apoptosis as a mechanism of immune privilege. Science 270:1189-1192.

Hahne M, Rimoldi D, Schroter M, Romero P, Schreier M, French LE, Schneider P, Bornand T, Fontana A, Lienard D, Cerottini J, and Tschopp J (1996). Melanoma cell expression of Fas (Apo-1/CD95) ligand: Implications for tumor immune escape. Science 274:1363-1366.

Halse A-K, Harley JB, Kroneld U, and Jonsson R (1999a). Ro/SS-A-reactive B lymphocytes in salivary glands and peripheral blood of patients with Sjögren's syndrome. Clin Exp Immunol 115:203-207.

Halse A-K, Tengnér $P$, Wahren-Herlenius $M$, Haga $H$, and Jonsson R (1999b). Increased frequency of cells secreting interleukin-6 and interleukin-10 in peripheral blood of patients with primary Sjögren's syndrome. Scand J Immunol 49:533-538.

Halse A-K, Wahren-Herlenius $M$, and Jonsson R (1999c). Ro/SS-A- and La/SS-B-reactive B lymphocytes in peripheral blood of patients with Sjögren's syndrome. Clin Exp Immunol 115:208-213.

Halse A-K, Marthinussen MC, Wahren-Herlenius $M$, and Jonsson R (2000). Isotype distribution of anti-Ro/SS-A and anti-La/SS-B antibodies in plasma and saliva of patients with Sjögren's syndrome. Scand J Rheumatol 29:13-19.

Henkart PA (1994). Lymphocyte-mediated cytotoxicity: Two pathways and multiple effector molecules. Immunity 1:343346 .

Hsu SM, Raine L, and Fanger H (1981). Use of avidin-biotinperoxidase complex $(A B C)$ in immunoperoxidase techniques: $A$ comparison between $A B C$ and unlabeled antibody (PAP) procedures. J Histochem Cytochem 29:577-580.

Humphreys-Beher MG, Brayer J, Yamachika S, Peck AB, and Jonsson R (1999). An alternative perspective to the immune response in autoimmune exocrinopathy: Induction of functional quiescence rather than destructive autoaggression. Scand J Immunol 49:7-10.

Huppertz B, Frank HG, and Kaufmann P (1999). The apoptosis cascade: Morphological and immunohistochemical methods for its visualization. Anat Embryol (Berl) 200:1-18.
Itoh N, Yonehara S, Ishii A, Yonehara M, Mizushima S, Sameshima M, Hase A, Seto $Y$, and Nagata S (1991). The polypeptide encoded by the cDNA for human cell surface antigen Fas can mediate apoptosis. Cell 66:233-243.

Jonsson R, Haga H-J, and Gordon T (2000). Sjögren's syndrome. In: Koopman WJ, editor. Arthritis and allied conditions: A textbook of rheumatology, 14 ed. Baltimore: Lippincott, Williams \& Wilkins, 1826-1849.

Jonsson R, Kroneld U, Backman K, Magnusson B, and Tarkowski A (1993). Progression of sialadenitis in Sjögren's syndrome. Br J Rheumatol 32:578-581.

Kiefer MC, Brauer MJ, Powers VC, Wu JJ, Umansky SR, Tomei LD, and Barr PJ (1995). Modulation of apoptosis by the widely distributed Bcl-2 homologue Bak. Nature 374:736-739.

Kong L, Ogawa N, McGuff HS, Nakabayashi T, Sakata KM, Masago R, Vela-Roch N, Talal N, and Dang H (1998). Bcl-2 family expression in salivary glands from patients with primary Sjögren's syndrome: Involvement of Bax in salivary gland destruction. Clin Immunol Immunopathol 88:133-141.

Kong L, Ogawa N, Nakabayashi T, Liu GT, D'Souza E, McGuff HS, Guerrero D, Talal N, and Dang H (1997). Fas and Fas ligand expression in the salivary glands of patients with primary Sjögren's syndrome. Arthritis Rheum 40:87-97.

Korsmeyer SJ (1992). Bcl-2 initiates a new category of oncogenes: Regulators of cell death. Blood 80:879-886.

Labat-Moleur F, Guillermet C, Lorimier P, Robert C, Lantuejoul S, Brambilla E, and Negoescu A (1998). TUNEL apoptotic cell detection in tissue sections: Critical evaluation and improvement. J Histochem Cytochem 46:327-334.

Loro LL, Vintermyr OK, Liavaag PG, Jonsson R, and Johannessen AC (1999). Oral squamous cell carcinoma is associated with decreased $\mathrm{bcl}-2 / \mathrm{bax}$ expression ratio and increased apoptosis. Hum Pathol 30:1097-1105.

Manganelli P, Quaini F, Andreoli AM, Lagrasta C, Pilato FP, Zuccarelli A, Monteverdi R, D'Aversa C, and Olivetti G (1997). Quantitative analysis of apoptosis and bcl-2 in Sjögren's syndrome. J Rheumatol 24:1552-1557.

Matsumura R, Kagami M, Tomioka H, Tanabe E, Sugiyama T, Sueishi M, Nakajima A, Azuma M, and Okumura K (1996). Expression of ductal Fas antigen in sialoadenitis of Sjögren's syndrome. Clin Exp Rheumatol 14:309-311.

Matsumura R, Umemiya K, Kagami M, Tomioka H, Tanabe E, Sugiyama T, Sueishi M, Nakajima A, Azuma M, Okumura K, and Sumida T (1998). Glandular and extraglandular expression of the Fas-Fas ligand and apoptosis in patients with Sjögren's syndrome. Clin Exp Rheumatol 16:561-568.

Mountz JD, Zhou T, Su X, Wu J, and Cheng J (1996). The role of programmed cell death as an emerging new concept for the pathogenesis of autoimmune diseases. Clin Immunol Immunopathol 80:S2-14.

Mullauer L, Mosberger I, Grusch M, Rudas M, and Chott A (2000). Fas ligand is expressed in normal breast epithelial cells and is frequently up-regulated in breast cancer. J Pathol 190:20-30.

Nagata S (1997). Apoptosis by death factor. Cell 88:355-365.

Nakamura H, Koji T, Tominaga M, Kawakami A, Migita K, Kawabe Y, Nakamura T, Shirabe S, and Eguchi K (1998). Apoptosis in labial salivary glands from Sjögren's syndrome (SS) patients: Comparison with human T lymphotropic virus-I (HTLV-I)- seronegative and -seropositive SS patients. Clin Exp Immunol 114:106-112. 
Negoescu A, Lorimier P, Labat-Moleur F, Drouet C, Robert C, Guillermet C, Brambilla C, and Brambilla E (1996). In situ apoptotic cell labeling by the TUNEL method: Improvement and evaluation on cell preparations. J Histochem Cytochem 44:959-968.

Oehm A, Behrmann I, Falk W, Pawlita M, Maier G, Klas C, Li-Weber M, Richards S, Dhein J, and Trauth BC (1992) Purification and molecular cloning of the APO-1 cell surface antigen, a member of the tumor necrosis factor/nerve growth factor receptor superfamily. Sequence identity with the Fas antigen. J Biol Chem 267:10709-10715.

Polihronis M, Tapinos NI, Theocharis SE, Economou A, Kittas C, and Moutsopoulos HM (1998). Modes of epithelial cell death and repair in Sjögren's syndrome (SS). Clin Exp Immunol 114:485-490.

Reichlin M, Rader M, and Harley JB (1989). Autoimmune response to the Ro/SSA particle is directed to the human antigen. Clin Exp Immunol 76:373-377.

Saas $P$, Walker PR, Hahne M, Quiquerez AL, Schnuriger V, Perrin G, French L, Van Meir EG, de Tribolet N, Tschopp J, and Dietrich PY (1997). Fas ligand expression by astrocytoma in vivo: Maintaining immune privilege in the brain? $\mathrm{J}$ Clin Invest 99:1173-1178.

Skarstein K, Nerland AH, Eidsheim M, Mountz JD, and Jonsson R (1997). Lymphoid cell accumulation in salivary glands of autoimmune MRL mice can be due to impaired apoptosis. Scand J Immunol 46:373-378.

Suda T, Okazaki T, Naito Y, Yokota T, Arai N, Ozaki S, Nakao $\mathrm{K}$, and Nagata $S$ (1995). Expression of the Fas ligand in cells of T cell lineage. J Immunol 154:3806-3813.

Suda T, Takahashi T, Golstein P, and Nagata S (1993). Molecular cloning and expression of the Fas ligand, a novel member of the tumor necrosis factor family. Cell 75:11691178.

Sumida T, Matsumoto I, Murata H, Namekawa T, Matsumura $\mathrm{R}$, Tomioka H, Iwamoto I, Saito $\mathrm{Y}$, Mizushima $\mathrm{Y}$, Hasunuma T, Maeda T, and Nishioka K (1997). TCR in Fas-sensitive T cells from labial salivary glands of patients with Sjögren's syndrome. J Immunol 158:1020-1025.

Surh CD and Sprent J (1994). T-cell apoptosis detected in situ during positive and negative selection in the thymus. Nature 372:100-103.
Taga K, Cherney B, and Tosato G (1993). IL-10 inhibits apoptotic cell death in human $\mathrm{T}$ cells starved of IL-2. Int Immunol 5:1599-1608.

Takahashi T, Tanaka M, Brannan Cl, Jenkins NA, Copeland NG, Suda T, and Nagata S (1994). Generalized lymphoproliferative disease in mice, caused by a point mutation in the Fas ligand. Cell 76:969-976.

Tengnér $\mathrm{P}$, Halse AK, Haga HJ, Jonsson R, and WahrenHerlenius M (1998). Detection of anti-Ro/SSA and anti-La/ SSB autoantibody-producing cells in salivary glands from patients with Sjögren's syndrome. Arthritis Rheum 41:22382248.

Thompson CB (1995). Apoptosis in the pathogenesis and treatment of disease. Science 267:1456-1462.

Vitali C, Bombardieri S, Moutsopoulos HM, Balestrieri G, Bencivelli W, Bernstein RM, Bjerrum KB, Braga S, Coll J, and de Vita $S$ (1993). Preliminary criteria for the classification of Sjögren's syndrome: Results of a prospective concerted action supported by the European Community. Arthritis Rheum 36:340-347.

Watanabe-Fukunaga $\mathrm{R}$, Brannan $\mathrm{Cl}$, Copeland NG, Jenkins NA, and Nagata S (1992). Lymphoproliferation disorder in mice explained by defects in Fas antigen that mediates apoptosis. Nature 356:314-317.

Yasuda M, Umemura S, Osamura RY, Kenjo T, and Tsutsumi $Y$ (1995). Apoptotic cells in the human endometrium and placental villi: Pitfalls in applying the TUNEL method. Arch Histol Cytol 58:185-190.

Zeher M, Szodoray P, Gyimesi E, and Szondy Z (1999). Correlation of increased susceptibility to apoptosis of CD4+ T cells with lymphocyte activation and activity of disease in patients with primary Sjögren's syndrome. Arthritis Rheum 42:1673-1681.

Zha H, Aime-Sempe C, Sato T, and Reed JC (1996). Proapoptotic protein Bax heterodimerizes with $\mathrm{Bcl}-2$ and homodimerizes with Bax via a novel domain $(\mathrm{BH} 3)$ distinct from $\mathrm{BH} 1$ and BH2. J Biol Chem 271:7440-7444. 